Fanum

Sociológico

\section{Forum Sociológico}

Série II

23 | 2013

Número 23

\title{
A tripla face da fronteira: reflexões sobre o dinamismo das relações fronteiriças a partir de três modelos de análise
}

\section{Carla Ladeira Pimentel Águas}

\section{(2) OpenEdition \\ Journals}

Édition électronique

URL : https://journals.openedition.org/sociologico/842

DOI : $10.4000 /$ sociologico.842

ISSN : 2182-7427

Éditeur

CICS.NOVA - Centro Interdisciplinar de Ciências Sociais da Universidade Nova de Lisboa

Édition imprimée

Date de publication : 1 novembre 2013

ISSN : 0872-8380

Référence électronique

Carla Ladeira Pimentel Águas, « A tripla face da fronteira: reflexões sobre o dinamismo das relações fronteiriças a partir de três modelos de análise », Forum Sociológico [En ligne], 23 | 2013, mis en ligne le 09 janvier 2014, consulté le 31 mars 2022. URL : http://journals.openedition.org/sociologico/842 ; DOI : https://doi.org/10.4000/sociologico.842

Ce document a été généré automatiquement le 31 mars 2022

(C) CICS.NOVA 


\title{
A tripla face da fronteira: reflexões sobre o dinamismo das relações fronteiriças a partir de três modelos de análise
}

\author{
Carla Ladeira Pimentel Águas
}

\section{Introdução: a irrequieta polissemia}

1 São muitas as lendas nas quais as fronteiras - representadas, nesta geografia do sonho, por portos, passagens, istmos, canais ou deltas - são guardadas por gigantes. Glissant (2006) explica que, por ser colossal, este personagem é capaz de ver os dois lados da divisa, o que lhe permite conceber tanto a necessária aliança, quanto a imprescindível particularidade de cada um deles. Segundo o autor, não é por acaso que, na maior parte das mitologias populares, o gigante é bom: ele tudo compreende da fronteira, porque vislumbra ambas as direções.

2 A ideia de fronteira povoa o imaginário por ser inquietante. 0 seu traçado é carregado de fenómenos: pode ser desenho - um risco no mapa ou um muro erguido sobre o chão e pode ser processo (Newman, 2006). Pode encarnar na concretude do cimento ou na abstração da metáfora. Pode ser usada para explicar o que separa os grupos sociais, mas também o que os une. Está assente em limites, bem como na sua transgressão (Santos, 2002). É possível recorrer ao termo para tratar da divisão entre nações, da globalização, das identidades, da expansão agrícola e de muitos outros temas, a partir de diferentes ângulos, muitos deles contraditórios entre si.

3 Portanto, é mesmo preciso ser gigante para ver a fronteira na sua multiplicidade. Ela une ou divide? Segundo Walter, como linhas divisórias de diferenciação espacial, temporal e cultural, as fronteiras distanciam a identidade interna da alteridade externa. Mas, como entre-espaços compartilhados, ligam-nas. Por um lado, estabelecem hierarquias entre o interior e o exterior, transformando os sujeitos em estrangeiros e 
ilegais. Simultaneamente, "constituem o terreno onde as identidades são vividas e imaginadas numa interação tensiva de estase cultural (diferença enquanto separação) e transgressão cultural (diversidade enquanto relação)" (Walter, 2006: 6). Portanto, quando falamos de fronteira, estamos perante um significante cuja flutuação, raiz da sua produtividade teórica, é, "ao mesmo tempo, fonte de ambiguidades que só podem resolver-se através de um esforço redobrado de contextualização" (Ribeiro, 2001: 472).

Limite, raia, borda, divisa, demarcação, extremidade, frente, margem, confim, entrelugar, limen - a variedade de palavras que buscam dar conta do significado de fronteira evidencia a sua polissemia. $O$ seu sentido literal provém de limes, a muralha imperial, destinada a manter de fora os bárbaros (Ribeiro, 2001). O aparecimento do termo, porém, ocorreu muito depois, no século XIII, a partir da palavra front - que designava o limite temporário e flutuante que separava dois exércitos numa batalha.

5 Na modernidade, o conceito foi associado à noção de soberania. A aparição da linha fronteiriça acompanhou o desenvolvimento da conceção moderna de espaço e participou do aperfeiçoamento da cartografia e das estratégias militares. Com o projeto colonial, a fronteira do Estado foi exportada para além da Europa e impôs-se ao planeta (Albaret-Schulz et al., 2004).

6 Com a emergência da ideia de globalização, diversos teóricos debruçaram-se sobre o tema das fronteiras nacionais. Muitos deles, embalados pelo sonho neoliberal, alardeavam a formatação de um mundo sem barreiras. Outros autores, no entanto, voltaram-se para a desconstrução deste discurso celebratório:

o processo histórico de descontextualização das identidades e de universalização das práticas sociais é muito menos homogéneo e inequívoco do que antes se pensou, já que com ele concorrem velhos e novos processos de recontextualização e de particularização das identidades e das práticas (Santos, 1993: 40).

7 A antropologia contribuiu para a elaboração de novas interpretações de fronteira. Na esteira de Leach, Hannerz (1997) destaca, por exemplo, a problematização da noção convencional de fronteiras políticas, ao descrever as dinâmicas de interpenetração das culturas. Perspetivas como esta passaram a centrar a análise em torno das microfronteiras, não só nas imediações de sociedades estabelecidas, mas justamente entre elas, nos seus interstícios. Desta forma, se a fronteira é entendida como barreira, pode também significar interface.

8 A interseção entre diferentes mundos - sociais, políticos, culturais, epistémicos etc. - foi chamada por Pratt (1992) de zona de contacto, definida pela autora como espaços sociais onde diferentes culturas se encontram, colidem e lutam entre si. Pratt usa este conceito para se referir ao espaço de encontro colonial - o que implica a existência de coerção e desigualdade.

9 Sousa Ribeiro destaca o papel do debate político, "em que as posições antagónicas em confronto se definem justamente pela concepção de fronteira que exibem” (2001: 466). Desta maneira, uma definição de fronteira como espaço de interação tenderá a assumir um valor crítico, enquanto conceções de fronteira como espaço de separação tendem a ser mais conservadoras. $\mathrm{O}$ autor também alerta para os riscos do uso eufórico do conceito. Se, em alguns casos, a fronteira pode proporcionar uma reconfiguração de identidades enriquecedora, noutros pode funcionar como espaço inabitável de exclusão e violência. ${ }^{1}$ Daí ser imprescindível não se perderem de vista as relações de poder estabelecidas no espaço fronteiriço. 
10 Portanto, seja qual for o ângulo a partir do qual a ideia de fronteira é interpretada, um aspeto perpassa todas as suas possíveis aceções: trata-se de um atributo de poder (Albaret-Schulz et al., 2004). A sua análise não pode deixar de se basear nas relações políticas que demarcam o jogo entre similitudes e diferenças.

11 Diante do seu amplo leque semântico, proponho agrupar os múltiplos sentidos de fronteira em três modelos de análise: fronteira que separa, fronteira como frente e fronteira que une. 0 primeiro reúne as abordagens que a descrevem como uma linha divisória que marca a separação entre diferentes espaços - tenham eles a forma concreta dos territórios nacionais, ou sejam simbólicos, como a diferenciação de identidades.

12 Já a fronteira como frente é um espaço que, à semelhança do front de batalha, avança para ganhar terreno. Vincula-se, portanto, à noção de frontier. Contrariando a aparente fixidez da conceção anterior, é uma fronteira em movimento, em progressivo distanciamento do centro. Em função desta distância, este é um espaço marcado por certa fluidez e criatividade, mas também por relações desiguais e pelo poder sem limites (Ribeiro, 2001).

13 Enquanto a fronteira como frente implica num movimento linear, a fronteira que une revela-se como um lugar de encontro e negociação. Não é linear, não avança. Portanto, deixa de lado a conceção de frontier para abraçar a ideia de borderland, que vem sendo tratada pelos estudos pós-coloniais como espaço in-between. Esta fronteira pode surgir $\mathrm{e}$ desaparecer, mudar de forma, e tem na fluidez uma das suas principais caraterísticas. Nesse sentido, o aquém da fronteira é um espaço ocupado, bem como o além da fronteira. E é na fronteira que esses mundos se encontram.

14 As três aceções aqui analisadas não são excludentes: num mesmo espaço-tempo, podem conviver diferentes formas de fronteira. Portanto, os três modelos de análise buscam traçar um inventário, que categoriza as diferentes versões do conceito. Não pretende estender tal segmentação à própria realidade, onde dinâmicas de aproximação e distanciamento podem competir, simultaneamente, dentro do jogo de relações. Afinal, a ponte que separa duas comunidades é a mesma que viabiliza a travessia.

15 Neste artigo, começo por explorar os três modelos de análise propostos, para depois refletir brevemente, a título de exemplo, sobre um estudo de caso: o subtil episódio da roda de Siriri² do quilombo de Mata Cavalo, uma comunidade situada no município de Nossa Senhora do Livramento, Estado de Mato Grosso, região Centro-Oeste do Brasil. A comunidade é designada como quilombo por ser uma coletividade com caraterísticas étnicas e identitárias diferenciadas, vinculadas à ancestralidade africana.

16 A partir de uma perspetiva metodológica qualitativa e através da observação direta, busquei descrever um dos pontos altos da festa em louvor a São Benedito, realizada numa das casas da comunidade. Através da dança do Siriri, discuti os efeitos da transformação da fronteira que separa na fronteira que une, realizando uma análise microscópica que sublinha a riqueza dos fenómenos fronteiriços.

\section{A fronteira que separa e a fronteira como frente}

17 Quando empregamos a palavra fronteira, a imagem que emerge com mais frequência é a da fronteira que separa: espaço de diferenciação; linha de demarcação em relação à qual algo está dentro ou fora (Hannerz, 1997). Esta fronteira está, portanto, vinculada a uma razão relacional e a formas de julgamento, discriminação e distinção. 
18 Para Albaret-Schulz et al. (2004), fronteira é uma construção territorial que põe a distância na proximidade. Assim, a proximidade espacial entre lugares é contradita pela presença de dispositivos que introduzem um afastamento - através de mecanismos de ordem material (barreira, muro, etc.) e ideológica (normas, representações, etc.). Esta distância é geralmente interpretada como um meio de proteção - de uma população, um território, um poder. Desta maneira, a fronteira é concebida como um sistema de controlo de fluxos através de uma filtragem. E, uma vez atravessada, induz a uma extraordinária alteração no corpo ou objeto que a cruzou, de forma que um pequeno movimento no espaço pode transformar um insider num forasteiro, ou o produto de mercado em contrabando.

19 Renard (apud Albaret-Schulz et al., 2004) sugere uma gradação conceitual entre as noções de limite e fronteira. O primeiro termo circunscreve dois conjuntos separados por descontinuidades na organização do espaço, não necessariamente estruturantes. Já a fronteira é estruturante, revelando um exercício de poder. Um exemplo bastante óbvio dos vínculos entre fronteira e poder é a ideia de fronteira nacional: fundacional para a modernidade, o seu traçado também implica a associação entre divisão espacial e significados culturais específicos (Shields, 2006).

Além disso, muitos dos estudos das fronteiras estão voltados para as transformações geradas pela globalização. ${ }^{3}$ Sob esta perspetiva, a fronteira nacional vem sendo confrontada por fenómenos tais como os fluxos crescentes de pessoas, informações, recursos e mercadorias. Mas, como vimos, a celebração da quebra de barreiras vem sendo questionada: Newman (2006), por exemplo, considera um equívoco que a dissolução de fronteiras seja entendida como um indicativo da transferência de poder entre diferentes elites - pois, no contexto da globalização, a remoção de fronteiras normalmente serve os interesses dos que as ergueram no passado.

21 O vislumbre de um mundo sem fronteiras vê-se também confrontado pela emergência de novas segmentações, tais como as divisões de cunho religioso, étnico ou político, que contradizem uma suposta tendência de uniformização do planeta. Outro exemplo insere-se no conceito de cidades duais, que chama a atenção para a natureza extremamente segregada das cidades, divididas entre zonas "fortificadas" das elites e os espaços ocupados pelas populações empobrecidas (Featherstone, 1995).

22 Considerada a partir de outro ângulo, a discussão sobre as fronteiras revela simultaneamente que em muitos contextos a fluidez de um mundo com limites ultrapassáveis jamais deixou de existir. Vista de perto, a realidade mostra que mesmo as divisões mais palpáveis, como os muros que separam dois países, apresentam certa porosidade. No decorrer da história, as determinações dos centros de poder jamais foram suficientes para inviabilizar plenamente a comunicação entre sujeitos apartados, o que denuncia certa abstração das linhas fronteiriças e a sua incapacidade de deter por completo as eventuais tendências de cosmopolitismo. Até em termos institucionais, sinergias socioeconómicas vêm gerando o aprofundamento de enlaces nos espaços transfronteiriços - nas chamadas cidades espelho - a exemplo dos projetos de inclusão social regional no contexto do Mercosul. ${ }^{4}$

23 Albaret-Schulz et al. (2004) consideram que dois aspetos foram frequentemente usados para legitimar os discursos de construção ideológica dos territórios: as fronteiras naturais e históricas. A topografia e a hidrografia, por exemplo, serviram como fundamentos para as divisões políticas. ${ }^{5}$ Porém, nem sempre tais caraterísticas respaldaram os traçados das fronteiras nacionais, a exemplo da colonização do Sul 
global, que lançou mão de narrativas legitimadoras próprias. O mapa africano revela isso com transparência: grande parte das suas linhas foi traçada a régua, dependendo basicamente das negociações entre os impérios colonizadores.

"Tais linhas são mais do que representações ou demarcações; elas são fronteiras virtuais que prefiguram linhas concretas na paisagem", observa Shields (2006: 227). o autor acrescenta que estas divisões podem ainda marcar a diferença entre estados radicalmente diferentes - "entre o "civilizado» e o «não civilizado», por exemplo" (idem). Portanto, o conceito de fronteira também pode ser utilizado para pisarmos num território bem mais fluido do que o das divisas nacionais: também se revela útil para se pensar nos processos de hierarquização do mundo, bem como nos mecanismos de construção das identidades.

Sousa Ribeiro afirma que construir o outro significa "construir a fronteira que dele me separa" (2001: 469). Desta forma, a fronteira torna-se a linha imaginária sobre a qual se projeta a noção de diferença e a partir da qual se torna possível a afirmação de identidade. Na modernidade, estes jogos de diferenciação foram extremados através de uma descrição do mundo pautada por dicotomias - entre negro/branco, civilizado/ selvagem, etc. Esta visão essencialista levou à formatação das identidades-fortaleza (Santos, 2002) que, em última análise, são o revés do cosmopolitismo.

De certa maneira, portanto, é possível dizer que as narrativas hegemónicas são caraterizadas por diversas formas de divisão, que moldam a maneira moderna de viver e compreender o mundo. É por este motivo que o esbatimento dessas barreiras - a transformação, no campo das sociabilidades, das fronteiras que separam em fronteiras que unem - é um processo emancipatório.

27 Antes de chegarmos a essa discussão, concentremo-nos no segundo modelo de análise: a fronteira como frente é o limite em expansão. É onde, em determinado tempo, se dá o avanço unilateral de um agente transformador sobre o espaço - o que implica a existência de um território, ainda que metafórico, sobre o qual avançar. Vincula-se, portanto, a uma geografia e a uma ação que tende a acabar-se. Está sempre em movimento - uma caminhada rumo ao que está para além dela - pois, quando este movimento cessa, a fronteira como frente transforma-se em fronteira que separa.

28 A frente de batalha (front) ilustra bem esta ideia: linha de soldados que confrontam diretamente o inimigo e que ganham terreno para o avanço das tropas. Outro exemplo é a conquista do Oeste, protagonizada pelos pioneiros norte-americanos. Acredito, aliás, que todas as expansões imperiais se dão através dessa aceção de fronteira.

Outros tipos de limite em expansão podem ser analisados sob este mesmo prisma, tais como as frentes agrícolas - que levam até confins selvagens ou vazios as benesses do avanço do progresso. Da mesma forma, a expressão "a última fronteira" (do que quer que seja) significa a extremidade do conhecido, aceitável e plausível. Quando a ciência se defronta com as fronteiras do conhecimento, é também no sentido de limite próximo à terra selvagem: "Deste lado, os campos cultivados; do outro, o grande desconhecido" (Hannerz, 1997: 21).

30 Em certa medida, esta interpretação está a meio caminho entre a fronteira que separa e a fronteira que une. Isso porque, por um lado, é uma zona limítrofe que divide um espaçotempo já transformado daquele que ainda não sofreu a ação do agente transformador. Por outro lado, esta fronteira não deixa de ser um lugar de encontro. O que está do lado de lá é um espaço preenchido - por povos, culturas, outros centros - e o confronto dá-se 
com maiores ou menores tensões. Outra vez, as relações de poder dão a tónica da análise.

31 As hierarquias, na fronteira como frente, comportam-se como os dois lados de uma moeda. A face interna - o interior dos seus limites - carateriza-se pela flexibilização das estruturas hierárquicas, em função do distanciamento dos núcleos de poder. Mas a face externa é a relação com o outro, aquele que está na fronteira ou para além dela. Neste caso, ao invés do enfraquecimento das hierarquias, há o esforço de sobreposição das novas sobre as antigas relações hierárquicas. Podem ocorrer negociações no espaço fronteiriço, mas estas são fragilizadas quando a frente de avanço se desloca para adiante, e o espaço deixa de ser limítrofe para ganhar a estabilidade do centro irradiador da expansão.

Só assim - através da sobreposição de hierarquias ou da transitória e condenada negociação entre hierarquias - a continuidade do avanço é possível. Trata-se, portanto, de um espaço de encontro, mas um encontro desigual. Não raro o outro é invisibilizado, liquidado ou expulso, para atender à tendência de continuidade do movimento.

No contexto da frente pioneira dos Estados Unidos, por exemplo, à medida que as fronteiras coloniais cediam lugar às fronteiras nacionais - ou que, digamos, as fronteiras como frente ganhavam fixidez e se transformavam em fronteiras que separam -, abriam também caminho para hierarquias endurecidas, inscritas nas noções de cidadania e nos seus significados mais exclusivistas: para os incluídos, uma nova era de autonomia; para os excluídos, a perda de status político, jurídico, social e pessoal (Adelman e Aron, 1999).

Esses e outros exemplos revelam uma noção de fronteira que, apesar de alguns elos em comum, em muito difere da aceção de fronteira que une. A última, entendida como espaço de interação, é potencialmente transformadora, não devido ao avanço sobre o outro, mas sim devido à articulação com o outro.

\section{À luz do crepúsculo: a fronteira que une}

35 A burlesca imagem de Charles Chaplin no filme Gold Rush, descrita por Shields (2006), traz à tona um outro espaço, para além do estar dentro ou do estar fora: o ator corre em ziguezague sobre a fronteira entre o México e os Estados Unidos, perseguido de um lado pela polícia e, do outro, por ladrões. Esta cena surreal ilustra a possibilidade de se pensar na fronteira em si como um terceiro lugar.

Segundo o autor, "fronteiras são normativamente definidas para serem atravessadas, não para serem percorridas. Se elas são seguidas, o seu status é alterado, transformando-se em virtuais, intersticiais ou liminares espaços de «interação»" (Shields, 2006: 229). Esta terceira aceção não se situa, portanto, de um lado ou do outro - e é por romper com a binaridade que, segundo Sousa Ribeiro (2001), este encontro entre diferenças é transgressor.

No conceito de fronteira, está sempre implícita uma determinada articulação entre centro e margem. Vimos que tal vínculo é pautado pelas relações de poder: de maneira geral, quanto maior a força irradiada pelo centro, mais rígidas serão as hierarquias e menos dinamismo existirá nas margens. Como sintetiza Boaventura Sousa Santos, para culturas dotadas de fortes centros, as fronteiras são pouco visíveis, "e isso é a causa última do seu provincianismo" (1993: 49). Mas, se as forças centrípetas não forem excessivas, as bordas podem revelar-se um território de criatividade. 
38 No seu sentido mais amplo, as relações sociais são sempre culturais e políticas representam distribuições desiguais de poder (Santos e Meneses, 2009). A metáfora da fronteira que une convida, portanto, ao deslocamento do foco, que é retirado dos núcleos estruturantes para se concentrar nos fenómenos marginais; aqueles que ocorrem nos instáveis espaços intersticiais.

Sousa Ribeiro (2001) lembra que os border studies, embora retendo a conotação de precariedade e mesmo arbitrariedade das distinções fronteiriças, concebem a fronteira como uma zona de encontro. Este espaço transgride, interliga, reconfigura e a sua riqueza está precisamente na justaposição de diversas influências. De natureza instável, pode ser metaforicamente entendido como um terreno movediço, onde acontecem o confronto e a intermediação - e onde o estabelecimento de um cânon único é impossível (Santos, 2002).

40 O espaço de encontro não é formado a partir do avanço no sentido geográfico. Pode emergir e desaparecer, desde que haja um ambiente propício à articulação com a diferença. É um lugar transitório e, de certa forma, precário e volátil. Como afirma Hannerz, "os cenários das zonas intersticiais parecem cheios de vida, mas não completamente seguros" (1997: 24). Sousa Ribeiro define esta fronteira como "um medium de comunicação, o espaço habitável em que o eu e o outro encontram uma possibilidade de partilha e, assim, a possibilidade de dar origem a novas configurações de identidade" (2001: 471). Ao introduzir movimento na compreensão das identidades, esta aceção contradiz a ideia monolítica de cultura: na esteira de Bakhtin, Sousa Ribeiro (2005) lembra que todo o ato cultural vive, essencialmente, nas fronteiras.

41 Bhabha (1994) utiliza a noção de ambivalência para caraterizar os processos desencadeados a partir do encontro com a diferença. Ele entende que, apesar da existência da diferenciação em relação ao outro, há simultaneamente a incorporação deste outro dentro do mesmo, no campo da representação. Esta abordagem desconstrói a ideia de relações binárias entre totalidades, abrindo margem para a indeterminação. Ao invés de centrar a sua atenção num lado e noutro, Bhabha crê que o que está no meio in-between - é que pode ser realmente revelador.

Neste sentido, Friedman (2001) alerta para que, não obstante as importantes conquistas políticas que a fixação na ideia de diferença veio possibilitar na teorização das identidades, ela também tende a ocultar o espaço existente nos interstícios dessa mesma diferença, a partir do qual são geradas novas narrativas identitárias. Assim, opta por substituir a imagem de mosaico pela de crepúsculo, para caraterizar os encontros interculturais:

A metáfora do mosaico silencia a maneira como a própria diferença se configura e reconfigura através de um processo de interação contínuo, ou seja, a maneira como o espaço intersticial se revela efetivamente lugar de constante migração, de um permanente movimento de vaivém (Friedman, 2001: 6).

Nesta zona crepuscular, não há regras predefinidas; tudo depende das articulações dadas na efemeridade do seu espaço-tempo. Em constante negociação do seu posicionamento, dá-se a perceber na sua mobilidade (Martins, 2001). Mas viver na fronteira não é uma tarefa fácil: como alerta Gruzinski (2001), referindo-se ao seu conceito de pensamento mestiço (eminentemente fronteiriço), este choca com hábitos intelectuais que levam a preferir os conjuntos monolíticos aos espaços intermediários.

Para discutir a fronteira, é preciso ter em conta os seus limites - a conturbada relação com a alteridade -, bem como as suas perturbadoras possibilidades. Este jogo entre 
limites e possibilidades pode ser ilustrado pelo encontro imaginário entre o Mesmo e o Diverso, descrito por Glissant:

o que se chama em toda parte a aceleração da história, que provém da saturação do Mesmo, como de uma água que transborda de seu continente, desbloqueou em toda parte a exigência do Diverso. Esta aceleração, levada pelas lutas políticas, fez com que os povos que ainda ontem povoavam a face escondida da Terra (como houve durante muito tempo uma face escondida da lua) tiveram que nomear-se diante do mundo totalizado. Se não se nomeassem, amputariam o mundo de uma parte de si mesmo (Glissant, 1981: 191).

No que se refere aos limites, a reformulação das identidades coloca-nos diante de encruzilhadas que nos conduzem ao desafio da alteridade. Segundo Durante (2007), no Ocidente, desde Platão, toda a aproximação do outro fecha a problemática num círculo vicioso, através da construção de aparatos interpretativos que pertencem a uma semiocracia, ou seja, a um horizonte de sentido único. Trata-se de integrar o outro no domínio do mesmo, dando origem ao exótico.

Said (2003) oferece um exemplo deste desterro. A partir do seu conceito de orientalismo, o autor considera que o Oriente ajudou a definir o Ocidente como contraposição, ontológica e epistemológica, à sua imagem - uma representação do outro como incapaz de representar a si mesmo. A estereotipia é o resultado evidente de tais processos, como sublinha Durante:

Se se mata o outro, é precisamente porque seu rosto foi substituído por um clichê. [...] o olhar do outro, a língua do outro, o corpo do outro, a cor do outro, o odor do outro, o desejo do outro, os valores do outro, a cultura do outro. Nessa perspetiva, o gelo do outro ressaltado pelo estereótipo antecipa o tempo de sua morte. É uma morte em efígie (Durante, 2007: 10).

Ou seja: para realmente se comunicar com o outro, o mesmo precisa de entrar na fronteira. Trata-se de uma relação ética, ou de uma ética na relação - que, para Lévinas ${ }^{6}$ (apud Estevam, 2008), deve sempre preceder a ontologia.

0 tema da alteridade inquietou diversos autores. Atento às transformações do seu tempo, Simmel (1983), por exemplo, viu nas interações entre os indivíduos o próprio fundamento da vida. Focado nas interações sociais ${ }^{7}$ do mundo urbano em ascensão, discutiu o individualismo frente aos processos modernos de universalização, criando pontes entre a experiência do sujeito e a organização social da modernidade. No contexto latino-americano e desde uma perspetiva pós-moderna, Canclini (1997) refletiu sobre as fronteiras entre o moderno e o chamado "popular", debruçando-se sobre as denominadas culturas hibridas.

Tais discussões, aqui brevemente apresentadas, oferecem pistas da complexidade do debate em torno da questão da alteridade. Nesse sentido, a palavra diálogo, tão desgastada pelo uso corrente, exige bem mais do que a abstrata conexão entre um emissor e um recetor, situados em polos opostos. Os sujeitos, simultaneamente emissores e recetores, precisam de se deslocar para o entre-lugar fronteiriço, despindose do conforto das relações de poder já cristalizadas para se lançarem no território instável e surpreendente da interseção de mundos. 


\section{Aproximações epistemológicas: a roda de Siriri como fronteira} densidade aos ténues fios que unem e dividem os grupos sociais no espaço de fronteira. A celebração, uma das mais famosas da comunidade, reúne diferentes grupos: na cozinha, nublados pelos vapores dos tachos, trabalhavam diversos sujeitos de dentro e fora da comunidade. $O$ anfitrião, Cizernando Santos, chegou a construir um empalizado de bambu e palha para abrigar quantos quisessem dormir nos dias de festa. 0 salão de baile e o oratório, feitos do mesmo material, também tinham o propósito efémero de servir às louvações de São Benedito. A própria preparação destas estruturas resulta de uma conjunção de forças que é estabelecida através de redes de entreajuda. transportando parentes e amigos de toda parte. À medida que a festa avançava, novos rostos iam-se incorporando na paisagem: políticos e proprietários de terras da região misturavam-se a quilombolas, trabalhadores da cidade, pequenos lavradores.

o sábado, chegou à festa de São Benedito o autocarro repleto de estudantes da Escola João Sato, do município de Araputanga (a cerca de $400 \mathrm{~km}$ de Livramento), que participavam numa viagem de estudos para conhecer de perto a realidade de um quilombo. Além disso, fizeram parte da festa diversos grupos de Siriri de outros municípios mato-grossenses e o grupo de dançantes do Congo ${ }^{8}$ de Livramento. Formouse ali, portanto, uma grande zona de encontro intercultural, marcada por maiores ou menores articulações entre os seus membros.

53 A gestão desta diversidade foi feita através de um princípio de organização que ampliava ou reduzia o espaço fronteiriço. Ao contrário das festas de santo realizadas na região, esta festividade mesclava a celebração religiosa com apresentações artísticas. Desta forma, o evento incluiu o espetáculo e a experiência: algumas partes destinavamse a ser vistas e outras vividas. artistas e espetadores: no rústico barracão de palha, que servia como palco para as exibições, a plateia era passiva e espremia-se encostada à parede para assistir as danças. Além da divisão no espaço, o uso de figurinos coloridos não deixava dúvidas sobre aqueles que poderiam ou não atravessar a linha imaginária que separava aquele que age daquele que assiste à ação.

Depois de várias apresentações, o encerramento foi feito pelo grupo de Siriri de Mata Cavalo, liderado por Cizernando, o anfitrião. Foi a única dança que trocou o salão pelo terreiro, ao ar livre. Sob o forte ressoar da percussão, os jovens, com roupas estampadas, apresentaram em fileiras as suas coreografias.

Não houve um desfecho da apresentação: o Siriri fez uma suave transição, quando as fileiras de dançantes se transformaram em roda. $O$ grupo do Congo foi o primeiro a entrar naquele espaço, integrando-se na dança. Depois, outros rostos foram ingressando na roda: quilombolas, membros de outros grupos de Siriri, estudantes e professores de Araputanga, amigos, parentes. As pessoas entravam na dança espontaneamente ou eram alegremente puxadas ao centro da roda pelos participantes. o círculo ficou enorme, ocupando todo o terreiro. Se, anteriormente, uma invisível fronteira que separa dividia os artistas dos espetadores, abriu-se, naquele instante, uma

Forum Sociológico, 23 | 2013 
fronteira que une, propícia às traduções interculturais e regida não pela argumentação, mas pelo corpo, pela performance, pela energia da percussão. Articulações mudas foram feitas, exclusivamente no campo simbólico.

Um exemplo foi o êxtase dos professores e alunos de Araputanga. Apesar das entrevistas e observações feitas pelos estudantes, a roda de Siriri foi o ponto que gerou os principais comentários depois da festa. Os participantes de Araputanga construíram posteriormente, para a escola e para o poder público, através de relatórios e monografias, uma imagem do que é Mata Cavalo. "Aquela roda é mágica; não sei como não caí, porque tenho labirintite", exclamava, por exemplo, uma das coordenadoras da viagem. Foi durante a dança que aquele grupo, oriundo de outra cultura, se sentiu mais próximo do que é a realidade quilombola. Neste sentido, vale a pena relembrar que:

Viver na fronteira significa viver fora da fortaleza, numa disponibilidade total para esperar por quem quer que seja. [...] Significa prestar atenção a todos os que chegam e aos seus hábitos diferentes, e reconhecer na diferença as oportunidades para o enriquecimento mútuo. Essas oportunidades facilitam novos relacionamentos, novas invenções de sociabilidade (Santos, 2002: 324).

Depois de assistir a tantas apresentações em que os movimentos eram coreografados, a roda de Siriri parecia um território de liberdade. Como espaço in-between, ali a tradição ganhou novos contornos. Cada um dançava à sua maneira: o rei do Congo fazia amplos movimentos com a capa vermelha, os estudantes inventavam os seus passos, eu mesma improvisei os meus próprios caminhos quando me vi no centro da roda.

Em determinado momento, a coroa do rei do Congo começou a ser usada como senha para a definição do parceiro. Colocar o chapéu em alguém para a escolha do par não é uma ideia nova; trata-se de um costume que anima bailes da zona rural de várias partes do Brasil. Não é, porém, uma tradição do Siriri e muito menos do Congo - a iniciativa surgiu espontaneamente.

60 Dentro daquele espaço em suspensão, instável e fugaz, membros de diferentes mundos brincavam a inventar outras formas de viver o Siriri. A tradição tornou-se, portanto, maleável e propícia às reformulações. A coroa do rei foi ali reinventada, reinterpretada, assumindo novas funções na fronteira.

\section{Conclusões: para além do Estado de Arte}

61 Vimos que a metáfora da fronteira representa uma forma de sociabilidade que se estabelece nas margens do encontro cultural. Diante da sua polissemia, optei por dividir o conceito em três modelos de análise: fronteira que separa, fronteira como frente e fronteira que une.

Vale recordar que a primeira aceção está vinculada a uma razão relacional e se refere ao que separa os grupos - tenha esta fronteira a forma concreta de um muro ou a subtileza das diferenças identitárias. A segunda está relacionada com o limite da expansão e implica, portanto, o avanço unilateral de um agente transformador sobre determinado espaço. Já a terceira expressa a fluidez dos processos sociais cosmopolitas: no entre-lugar, a justaposição de diversas influências permite a emergência de novas configurações de identidade. A pertença simultânea a mais de um universo cognitivo contradiz a ideia monolítica de cultura - que é então concebida em constante transformação. 


\section{BIBLIOGRAPHIE}

ADELMAN, J. e A. Stephen (1999), From Borderlands to Borders: Empires, Nation-States, and the peoples in between in North American history, disponível em http://www.historycooperative.org/journals/ $\mathrm{ahr} / 104.3 /$ ah000814.html, acesso em 02/08/2009.

ALBARET-SCHULZ, C., A. Beyer et al. (2004), La frontière, un object spatial en mutation, disponível em http://espacestemps.revues.org/document842.html, acesso em 28/07/2009.

BHABHA, H. (1994), The Location of Culture, Londres e Nova Iorque, Routledge.

CANCLINI, N. (1997), Culturas híbridas: estratégias para entrar e sair da modernidade, São Paulo, Edusp.

DURANTE, D. (2007), “Alteridade e reflexão intercultural: seus objetivos no quadro das práticas artísticas em geral e da fala literária em particular", Revista Sociopoética, disponível em http:// eduep.uepb.edu.br/sociopoetica/publicacoes/v1n1.html, acesso em 25/05/2011.

ESTEVAM, J. (2008), "O reconhecimento da alteridade como possibilidade de construção de um novo paradigma na cultura ocidental em Joel Birman e Emmanuel Lévinas", Horizonte, vol. 6, 12, pp. 169-179.

FEATHERSTONE, M. (1995), A globalização da complexidade: pós-modernismo e cultura do consumo, disponível em http://www.anpocs.org.br/portal/publicacoes/rbcs_00_32/rbcs32_07, acesso em $29 / 03 / 2013$

Forum Sociológico, 23 | 2013 
FRIEDMAN, S. (2001), "O «falar da fronteira», o hibridismo e a performatividade: teoria da cultura e identidade nos espaços intersticiais da diferença”, Revista Crítica de Ciências Sociais, 61, pp. 5-28.

GLISSANT, E. (1981), O Mesmo e o Diverso, disponível em http://www.ufrgs.br/cdrom/glissant/ glissant.pdf, acesso em 23/04/2009.

GLISSANT, E. (2006), Não há fronteira que não se ultrapasse, disponível em http:// diplomatique.uol.com.br/acervo.php?id=1962\&tipo=acervo, acesso em 25/05/2011.

GRUZINSKI, S. (2001), o pensamento mestiço, São Paulo, Companhia das Letras.

HANNERZ, U. (1997), “Fluxos, fronteiras, híbridos: palavras-chave da antropologia transnacional", Mana, vol. 3, 1, pp. 7-39.

KOLOSSOV, V. (2006), “Theoretical Limology: Postmodern analytical approaches”, Diogenes, vol. 52,2, pp. 11-22.

MALDONADO-TORRES, N. (2008), “A topologia do Ser e a geopolítica do conhecimento. Modernidade, império e colonialidade”, Revista Crítica de Ciências Sociais, 80, pp. 71-114.

MARTINS, R. (2001), “O paradoxo da demarcação emancipatória: a fronteira da época da sua reprodutibilidade icónica”, Revista Crítica de Ciências Sociais, 59, pp. 37-63.

NEWMAN, D. (2006), "Border and Bordering: towards an interdisciplinary dialogue", European Journal of Social Theory, vol. 9, 2, pp. 171-186.

PRATT, M. L. (1992), Imperial Eyes: Travel writing and transculturation, Londres/Nova Iorque, Routledge.

RIBEIRO, A. S. (2001), “A retórica dos limites. Notas sobre o conceito de fronteira”, in B. Santos (org.), Globalização: fatalidade ou utopia?, Porto, Afrontamento, pp. 463-488.

RIBEIRO, A. S. (2005), “A tradução como metáfora da contemporaneidade. Pós-colonialismo, fronteiras e identidades”, in A. G. Macedo e M. E. Keating (orgs.). Colóquio de Outono: Estudos de tradução. Estudos Pós-Coloniais, Braga, Universidade do Minho, pp. 77-87.

SAID, E. (2003), Orientalismo: representações ocidentais do Oriente, Lisboa, Cotovia.

SANTOS, B. S. (1993), “Modernidade, identidade e cultura de fronteira”, Tempo Social, 5, pp. 31-52.

SANTOS, B. S. (2002), A crítica da razão indolente. Contra o desperdício da experiência, Porto, Afrontamento.

SANTOS, B. S. (2003), “Dilemas do nossos tempo: globalização, multiculturalismo e conhecimento", Currículo sem fronteiras, vol. 3, 2, pp. 5-23.

SANTOS, B. S. e M. P. Meneses (2009), "Introdução”, em B. Santos e M. P. Meneses (orgs.), Epistemologias do Sul, Coimbra, Almedina/CES, pp. 9-19.

SHIELDS, R. (2006), "Boundary-thinking in theories of the present: the virtuality of reflexive modernization", European Journal of Social Theory, vol. 9, 2, pp. 223-237.

SIMMEL, G. (1983), Sociologia, São Paulo, Ática.

WALTER, R. (2006), Transferências interculturais: notas sobre trans-cultura, multi-cultura, diásporas, disponível em http://whttp://www.uepb.edu.br/eduep/sociopoetica/publicacoes/v1n1/ v1n1_artigo05.html, acesso em 26/05/2011. 


\section{NOTES}

1. $O$ autor exemplifica que os espaços fechados dos aeroportos internacionais, onde os viajantes a quem foi recusada a entrada aguardam o momento de expulsão, tipificam de modo dramático a distopia de um não-lugar fronteiriço.

2. Siriri é uma dança típica, feita em roda ou fileiras, que anima as festas da região.

3. O processo de globalização e os seus impactos sobre as fronteiras nacionais geraram uma nova área de estudos: limology (Kolossov, 2006).

4. Sobre o tema, cf. as ações do Projeto Mercocidades, disponíveis em http:// www.mercociudades.org/pt-br.

5. Recorrendo a Fourny-Kober, os autores acreditam que hoje a tendência é inversa: há uma extraordinária operação de ressemantização da natureza, a fim de justificar os projetos territoriais transfronteiriços.

6. Porém, para Maldonado-Torres (2008), a alteridade defendida por Lévinas permanece agarrada às formações espaciais de cariz imperial: é limitada pela sua filiação étnica e pelo comprometimento religioso.

7. O autor substitui a palavra socialização pelo conceito de sociação, entendido como formas de cooperação entre os indivíduos.

8. Congo é uma dança dramática existente em várias partes do Brasil, sob diversas versões. Em Mata Cavalo, é um teatro a céu aberto que representa a guerra entre dois reinos.

\section{RÉSUMÉS}

Este artigo consiste numa reflexão acerca do conceito de fronteira. Diante da polissemia da palavra, divide a aplicação do termo em três modelos de análise: a fronteira que separa, a fronteira como frente e a fronteira que une, caraterizando cada um deles em suas particularidades e possibilidades. Para ilustrar tal reflexão, recorre ao exemplo da dança do Siriri, realizada na comunidade de Mata Cavalo, Brasil, explorando a complexidade dos fenómenos fronteiriços.

This paper is a theoretical reflection about the concept of border. Facing the polysemy of the word, the term is divided into three analytical models: the separating border, border as a front, and unifying border, characterizing each of them in its particularities and possibilities. Discusses the example of the traditional dance of "Siriri", in Mata Cavalo, Brazil, to explores the phenomena "in-between".

\section{INDEX}

Palavras-chave : fronteira, alteridade, cosmopolitismo

Keywords : border, otherness, cosmopolitanism 


\section{AUTEUR}

\section{CARLA LADEIRA PIMENTEL ÁGUAS}

Universidade de Coimbra. Doutoranda do Programa de Doutoramento em Pós-Colonialismos e Cidadania Global do Centro de Estudos Sociais e Faculdade de Economia da Universidade de Coimbra; bolseira da Fundação para a Ciência e a Tecnologia (carlaaguas@gmail.com) 